International Journal of Applied Linguistics \& English Literature

ISSN 2200-3592 (Print), ISSN 2200-3452 (Online)

Vol. 1 No. 5; September 2012 [Special Issue on General Linguistics]

\title{
Some Major Steps to Translation and Translator
}

\author{
Mohammad Reza Hojat Shamami (PhD student of English Translation) \\ National Academy of Sciences, Armenia \\ Tel: 0037498823592 E-mail: davemrh@yahoo.com
}

Received: 31-07- 2012

doi:10.7575/ijalel.v.1n.5p.242
Accepted: 31-08- 2012

Published: 03-09- 2012

URL: http://dx.doi.org/10.7575/ijalel.v.1n.5p.242

\begin{abstract}
This work is an overview of the main issues at the core of theorizing translation practice and the features of a good translator or how to be a good translator and of course what are the Skills to become a Freelance Translator and Translation process. In this world of science and technology there is knowledge explosion every day. This knowledge which is generally written in the English language needs to be transmitted in various languages so that people who do not know how to speak and write the original language can get the knowledge necessary for industrial development and technological innovation to keep up with the rest of the world. To transmit this knowledge effectively, there is a need for competent translators in various languages.
\end{abstract}

Keywords: Translation, Translator, SL, Accommodation, Text

\section{Introduction}

These days, people all across the globe generally believe that translation is just the involuntary substitution of languages, and therefore anybody can be a translator if she or he knows a foreign language. This perception is completely wrong, just having a good knowledge of foreign languages does not give any $100 \%$ assurance that a translation will be rendered reasonably well. In simple words translation requires skill to make the right and good analysis of the meaning in the target language (Steiner, 1975). Moreover, a translator must be aware of the essence of the subject besides having a fine awareness of the language, including language rules, and spelling rules. However, as the world is getting more globalize, in the past couple of years we are coming across the greatest challenge of text conversion and that is how to find the proper equilibrium between conveying the sense and beauty of the initial text and making the target conversion more efficient and effective. Only talented translators are competent of finding this sense of balance. So having a superior knowledge of the translation subject is just a part of the translation process (Richard, 1953).

\section{Significance of the Research}

It is through translation we know about all the developments in communication and Technology and keep abreast of the latest discoveries in the various fields of knowledge, and also have access through translation to the literature of several languages and to the different events happening in the world. India has had close links with ancient civilizations such as Persian, Greek, Egyptian and Chinese. This interactive relationship would have been impossible without the knowledge of the various languages spoken by the different communities and nations. This is how human beings realized the importance of translation long ago. Needless to mention here that the relevance and importance of translation has increased greatly in today's fast changing world. Today with the growing zest for knowledge in human minds there is a great need of translation in the fields of education, science and technology, mass communication, trade and business, literature, religion, tourism, etc (Gilson, 1977 ). Broadly speaking, translation turns a text of source language (SL) into a correct and understandable version of target language (TL) without losing the suggestion of the original(Fillmore, 1986). Many people think that being bilingual is all that is needed to be a translator. Being bilingual is an important prerequisite, no doubt, but translation skills are built and developed on the basis of one's own long drawn-out communicative and writing experiences in both the languages. As a matter of fact translation is a process based on the theory of extracting the meaning of a text from its present form and reproduces that with different form of a second language.

Conventionally, it is suggested that translators should meet three requirements, namely, 1)Familiarity with the source language, 2) Familiarity with the target language, and 3) Familiarity with the subject matter to perform the job successfully. Based on this concept, the translator discovers the meaning behind the forms in the source 
International Journal of Applied Linguistics \& English Literature

ISSN 2200-3592 (Print), ISSN 2200-3452 (Online)

Vol. 1 No. 5; September 2012 [Special Issue on General Linguistics]

language (SL) and does his best to reproduce the same meaning in the target language (TL) using the TL forms and structures to the best of his knowledge(Holt, 1986).

Naturally and supposedly what changes is the form and the code and what should remain unchanged is the meaning and the message Larson, Therefore, one may discern the most common definition of translation, i.e., the selection of the nearest equivalent for a language unit in the SL in a target language. Computers are already being used to translate one language into another, but humans are still involved in the process either through pre-writing or post-editing. There is no way that a computer can ever be able to translate languages the way a human being could since language uses metaphor/imagery to convey a particular meaning. Translating is more than simply looking up a few words in a dictionary (Wittgensteinl, 1953). A quality translation requires a thorough knowledge of both the source language and the target language. Successful translation is indicative of how closely it lives up to the expectations as: reproducing exactly as for as possible the meaning of the source text, using natural forms of the receptor/target language in such a way as is appropriate to the kind of text being translated and expressing all aspects of the meaning closely and readily understandable to the intended audience/reader. Technically, translation is a process to abstract the meaning of a text from its current forms and reproduce that meaning in different forms of another language. In fact, for a translator knowledge of two or more languages is essential. This involves not only a working knowledge of two different languages but also the knowledge of two linguistic systems as also their literature and culture. Such translators have been seen to possess various qualities which we shall briefly discuss later. Linguistically, translation consists of studying the lexicon, grammatical structure, communication situation, and cultural context of the source language and its text, analyzing it in order to determine its meaning, and then reconstructing the same meaning using the lexicon and grammatical structure which are appropriate in the target language and its cultural context (Dollerrup, 1992).

\section{Overview of the Research}

In practice, there is always considerable variation in the types of translations produced by various translators of a particular text. This is because translation is essentially an Art and not Science. So many factors including proficiency in language, cultural background, writing flair, etc. Translation turns a communication in one language into a correct and understandable version of that communication in another language. Sometimes a translator has to take certain liberties with the original text in order to re-create the mood and style of the original. This, in other words is called 'accommodation. This has three dimensions: cultural accommodation; collocation accommodation; ideological accommodation; and aesthetic accommodation. Accommodation is considered a synonym of adaptation which means changes are made so the target text produced is in line with the spirit of the original. Translation is not merely linguistic conversion or transformation between languages but it involves accommodation in scope of culture, politics, aesthetics, and many other factors (Nida, 1969).

A translator does need certain tools to help him out in moments of difficulty. These tools can be in the form of good monolingual and bilingual dictionaries, encyclopedias, e-dictionaries, glossaries of technical and standard works, etc. pertaining to the SL text. He must have patience and should not be in a hurry to rush through while translating any text. He should not hesitate in discussing with others the problems that he may come across. Moreover, he should not shy away from conducting micro-research in order to arrive at proper and apt equivalents. In short, he should be a competent and proficient bilingual, familiar with the subject/area of the SL text chosen for translation. He should never try to insert his own ideas or personal impressions in the TL text. His objective should be to convey the content and the intent of the SL text as exactly as possible into the TL text. The job of a translator is very rewarding and intellectually stimulating finally, a few words (based upon my close understanding about translation study and activity) for up-coming translators and translation-lovers (Labov, 1972). To translate from one language into another has never been an easy endeavor. It is an exercise both painstaking and cumbersome and only those who have engaged themselves with translation work can realize the complex character of this Art. I have been associated with translation work for over three decades translating from English, more especially, from Kashmiri/Urdu into Hindi and back (Di Petro, 1968).

\section{Statement of the Problem}

Focusing on this fact, (Chomsky, 1965) how can someone turn into a good translator? If you are serious about becoming a successful translator, you must be able to fulfill or follow the following criteria:

1. The first and most important step is reading of different translations of different types of texts. An effective translating requires first-class knowledge, so approachable skills should be developed before performing any text conversion. An excellent translator has a complete knowledge of both source and target speech, so you must 
International Journal of Applied Linguistics \& English Literature

ISSN 2200-3592 (Print), ISSN 2200-3452 (Online)

Vol. 1 No. 5; September 2012 [Special Issue on General Linguistics]

understand the diverse genres in both source and target verbal communication. It helps in improving reading aptitude in general, and gives insights, which can be subconsciously useful.

2. The second most vital talent required is the potential to write appropriately in both source and target languages. Writing is the chief work of a text converter. You should be well aware of different styles of writing and morals of editing in both source and target language. Factors like editing and proper punctuation usage increase the value and readability of the translation.

3. You should have listening ability to understand and alertness to grasp various expressions, idioms, and specific vocabulary and their uses. This talent is like an intuition and can't be developed easily, so to a certain extent it requires regular practice. Language intuition is like a necessity for all those who want to be proficient translators.

4. The act of translating is like accepting the significance of the source text within the framework of the source-language discourse. Now in order to enlarge this understanding, you must make yourself aware with cultural divergence and the diverse strategies present in the source and target verbal communication.

5. You should also be well aware of diverse registers, styles of speaking, and social stratification of both source and target languages. This socio-cultural awareness helps in improving the quality of translations to a large level. It is very important to understand that the work of translating takes place in the socio-cultural framework; as a result it is very vital to evaluate translating activity only within a social perspective.

6. In order to develop excellent translation proficiency, you have to become yourself attentive of different knowledge-providing sources like bilingual dictionaries, encyclopedias and learn how to utilize them. Now using dictionaries requires a very technical proficiency. Words have diverse meanings in different circumstance, and therefore you have to perform a repetitive exercise to know the projected meaning of words in a specific situation.

7. In addition to this you should know the sentence structure of indirect speech and different figures of speech in the source language like hyperbole, irony, and meiosis. Having detail knowledge of these figures of speech will further help in changing your flaccid knowledge into active talent.

\section{Objectives and Purposes of Research}

It is important that translators are familiar with the product they are translating and also with the tools they are using. The translation process is not the replacement of one word with another, but the formation of concepts in another language. Knowledge of the product being translated provides more understandable products to the end user. Time and resources for educating translators should be planned well in advance.

\section{Methodology}

Provide the translators with tools that increase productivity and that prevent translation of non-textual application data. When purchasing or developing a translation tool, the following features should be included. An editor that provides the ability to show displays that would be seen by the end user, and the ability to translate the textual data on the system but still protect the parts of the application that are not textual data. The editor should also include functions such as scan and replace, find, copy, move, and delete. A dictionary functions to provide consistency of words and phrases throughout the product. A validation process to check translation errors that might cause the application to malfunction. A merge function that provides the ability to merge the translated text into a new version of the original text. This merge function allows for translating only new text, and saves time and effort. A print function for validation purposes (Cau Simon, 1983).

\section{Literature Review/Research Background}

The Asian languages, particularly Persia, Japanese, Chinese, Korean, and Vietnamese, represent a significant part of the translation industry in the United States, especially on the West Coast(Antal, 1963). Some agencies specialize in only Asian languages or even just one or two of them. Still others make the brunt of their money from these languages. First, a brief clarification. Although Asia certainly includes India, Nepal, Tibet, Sri Lanka, as well as Malaysia, Indonesia, Australia, New Zealand and numerous other fascinating and important nations, this article will address only those languages which fall in the Sino group (Chinese, Vietnamese, Khmer, Burmese, Thai, Laotian, etc.) or the Altaic group (Korean and Japanese; Turkish is omitted for geographical reasons)( Benjamin, 1992). Apologies to the numerous other languages of the region, but they come from different families and are not relevant to this discussion. For convenience, I'll refer to the above languages as the Asian languages. Please also note that when I refer to European languages, I mean (Bloomfield, 1993) those members of the Romance, Germanic, or Baltic-Slavic families. This excludes Basque, Hungarian, and Finnish, whose origins have nothing to do with PIE (Proto Indo-European). 
International Journal of Applied Linguistics \& English Literature

ISSN 2200-3592 (Print), ISSN 2200-3452 (Online)

Vol. 1 No. 5; September 2012 [Special Issue on General Linguistics]

Modern Asian languages are much older than most modern Indo-European languages. French, Spanish and the other Romance languages all find their origins in Latin. English, German, and the other Germanic languages find their origins in Proto-Germanic (Brower, 1959). Baltic-Slavic is the original form of the current Baltic languages and Slavic tongues which include Russian and others. Note that all the proto-forms of these languages date from roughly 100-200 C.E., or even more recent. Asian languages lack much of the linguistic equipment we take for granted in an Indo-European tongue (Benjamin, 1992). For instance, neither Japanese nor Chinese distinguish the singular or plural unless absolutely necessary, they have no verb tenses as we are used to them in say French or Russian, no gender, cases, articles, or declensions as we know them in English, Spanish, or German(Antal, 1963). Asian languages also lack verb tenses as we think of them in English. At best, Japanese has a perfect and imperfect tense. For instance, we cannot say, "The Bridge collapsed tomorrow," in English (if you're wondering why we would need to say this, recall the collapse of a bridge in Seoul, Korea. I heard about this event only one hour after it happened, around 3:00 p.m. in California. Thus, it was already tomorrow in Korea, requiring me to answer the question "When did it happen?" with the statement, "The Bridge collapsed tomorrow."). In Japanese, there is no such problem. Because the event is complete, the perfect tense is used and an adverb of time indicating tomorrow is added (Brislin, 1976).

Moreover, Japanese (along with Korean) can omit virtually everything from a sentence which is not vital. The subject is rarely expressed in a sentence (and unlike Spanish, is not specified by the verb conjugation because there is none). Objects are often dropped. In its conversational form, many Japanese statements consist of nothing more than an adverb or adjective plus a verb (making eavesdropping somewhat more difficult than it is in English).Not only do these languages differ vastly from English,( Creas, 1997) but the cultural and historical backgrounds do as well. Virtually all European languages can trace at least some of their history through the Roman Empire and back to the ancient Greeks. The Asian languages find much of their cultural heritage in ancient Chinese history and philosophy, but are also influenced by many other sources, including Buddhism (Dollerrup, 1992). If you're translating into an Asian language, you have to deal with a major technical issue. Unlike the European languages which have agreed to use ASCII as the standard way of expressing the Roman alphabet (and recall that Spanish made an official modification a few years ago to accommodate this, and Germany did the same more recently), there is as yet no general agreement about how to deal with the so-called two-byte languages (which include most of the Asian languages, plus some others). You have probably been wondering how you look up a Chinese character in a dictionary. It depends. If you know the pronunciation, you might peruse that section of the dictionary and scan for it. This can take considerable time, but it is often faster than looking up the character in a character dictionary (Brislin, 1976).

This leads to another problem. While there are reasonably good if not excellent specialized dictionaries for the European languages, there are few if any for the Asian languages. So when Asian language translators take more time to deal with terminological issues, this is part of the reason. And for lack of good, current reference materials, many Chinese translators have to struggle with this issue and use what they know to be outdated or overly generic terminology simply because they can do no better. This is neither an apology nor a defense, just a statement of fact (Abangma, 1987). Translators of Asian languages live in a world of logistical nightmares compared to their European counterparts. And, the nightmare only gets worse when we consider the technology (Anderson, 1971).

\section{Results and Discussions}

All above-mentioned cases illustrate a remarkable and rich history of translation and major changes it caused in the history of our beloved country, Iran. Finally, we should know that it takes much more to be a good and skilled translator. Talented translators are not made overnight, it definitely requires a significant investment in both source and target speech. For every talented text (Benjamin, 1992) converter, switching simultaneously between two universes is one of the most demanding tasks lot of training, learning, and experience are needed to turn someone into a good translator. When engaging translators for your work, be sure to give them a detailed briefing on the work to be done (Brower, 1956). This will help minimize any misunderstanding and make the process more efficient. As professional translators we are supposed to improve our quality all the time. This is done to make our translations perfect and gaps between one source language to one target language can be minimized. In this case, we are supposed to watch over the key differences of the language pairs we are handling. The first noteworthy conclusion we can draw from this paper is that translation is teachable because, on the one hand, it is a craft and consequently teachable as are other crafts; on the other hand, it is closely related to teaching language itself, although it is vital to make a distinction between the two. Another important point is that those engaged in teaching translation to students who are learning the target language along with translation should be aware that they are 


\section{International Journal of Applied Linguistics \& English Literature \\ ISSN 2200-3592 (Print), ISSN 2200-3452 (Online) \\ Vol. 1 No. 5; September 2012 [Special Issue on General Linguistics]}

teaching two different things at the same time and that they should use a congruent eclectic method applicable to both. Believing that translation is a teachable craft they should help their students get an insight into the nature of translation and recognize that it is vital for them to pay attention to translation theories while honing their translation and language skills (Cau Simon, 1983). They should also be aware that ignoring the above-mentioned points leads to students' confusion, lack of motivation, and loss of interest in the curriculum.

\section{Conclusion}

In short, translation has a very wide and rich history in West. Since its birth, translation was the subject of variety of research and conflicts between theorists (Richard, 1953). Each theorist approaches it according to his viewpoint and field of research, the fact that gives its history a changing quality. It can also be concluded that translation process in Iran has been applied extensively since time immemorial to transfer the knowledge of varied scientific disciplines and literature from other languages into Persian and vice versa. The process made it possible for scientists and scholars to take advantage of scientific achievement of other nations in different areas. Within a specified period of time, translators of Iran used translation to expand and introduce Iranian culture, art and ideology to other nations. Finally, translation has been not only a means of preserving Iranian historical, scientific and cultural inheritance left from the distant past which was in danger of destruction as a result of invasion and war but also, translation from other languages has led to literary and political revolutions in Iran especially, in late nineteenth and the beginning of twentieth century.

\section{References}

Abangma, S.N. (1987). Modes in Denya Discourse. Summer Institute of Linguistics Publications in Linguistics: Dallas. 279P.

Anderson, J. M. (1971). The Grammar of Case. Towards a Localistic Theory. Cambridge: University Press. 219p. Antal, L. (1963). Interpretation and Transformation. Linguistics. NY: University Press.

Ballard, D. (1971).The Deep and Surface structure Grammar of interclausal Relations. Dordrecht.Holland.118p. Benjamin, W (1992). The Task of the Translator, Illuminations. Harry Zohn.Fontana.

Bloomfield, L. (1993). Language and Translation. New York: Henry Holt and Co.

Brislin, R. W. (1976). Back translation for cross - cultural research. New York: Garden Press.216P.

Brower, R. A. (1959). On Translation. Cambridge: Cambridge University Press.

Bunkowske, E. W. (1956). Religious Words! Which and Where? The Bible Translator. Cambridge: Harvard University Press. 231P.

Cau, S. C. ( 1983). The Nature and Limitations of Shakespeare translation. New York: Academic Press. Chomsky, N. (1965). Aspects of the Theory of Syntax. Cambridge: Cambridge University Press.

Crease, R. (1997). Hermeneutics and the Natural Sciences. Dordrecht: Kluwer Academic Publishers.

Crystal, D. (1973). Current Trends in translation Theory. The Bible Translator. Prague. Academia publishing House. 329P.

Di, P. (1968). Contrastive Analysis and the Notions of Deep and Surface Structure. Washington. DC.

Dollerrup, C. (1992). Teaching Translation and Interpretation. Amsterdam and Philadelphia. John Benjamin Publishing Company.

Fillmore, C. J. (1986). The Case of Case. Universals in Linguistic Theory. New York. Holt Rinehart and Winston. Gilson, P. (1997). Image and Logic. Chicago and London: University of Chicago Press.

Labov, W. (1972). Sociolinguistic Patterns. Philadelphia: University of Pennsylvania Press. 344P.

Nida, E. A. (1969). Theory and Practice of Translation. Leiden. Brill. 218 p.

Richard, A. (1953). Toward a Theory of Translating Studies in Chinese Thought. Chicago: University of Chicago Press. 262P.

Steiner, G. (1975). After Babel aspects of Language and Translation. London: Oxford University Press. 507P. Wittgensteinl, P. (1953). New York. Macmillan. Oxford. Blackwell. 232P. 